\title{
Probiotics for irritable bowel syndrome: Should we give them full names?
}

Irritable bowel syndrome is a highly prevalent issue with huge social and financial effects, and above all a significant impact on the people who suffer from it (1); thus it is a common reason for consulting a gastroenterologist (2). Unfortunately, today we still are far from having a curative therapy available for IBS.

Among the therapeutic approaches assessed during the last few decades, intestinal flora modifications have drawn the main focus of attention. A decade ago, bacterial overgrowth was suggested as a potential physiological basis for IBS (3), and antibiotics brought about sound results in clinical trials (4) that sadly did not translate into solutions for IBS in clinical practice. However, several studies question the bacterial overgrowth hypothesis (5). Probiotics represent an alternative way of modifying the microbiota, and have noticeably gained people's confidence based on the healthy halo that the media have assigned them in the past decade.

Why probiotics for IBS? In addition to experimental data in support of the presence of bacterial overgrowth in patients with IBS (6), other evidence suggests qualitative colonic flora changes in these patients, particularly regarding bifidobacteria, which might facilitate a proliferation of gas-producing species (7) or modifications induced by their metabolic byproducts, most especially fatty acids (8). The microbiota not only has intraluminal effects, but may also modify intestinal physiology beyond the colonic lumen, and evidence is available on the capability of probiotics to modulate immune responses, modify neuromuscular disorders, and even influence the brain-bowel axis outside of the gut (9).

The efficacy of probiotics in IBS has been assessed by multiple studies, (10) and several meta-analyses and systematic reviews have been published $(11,12)$; however, they have no clear role within the therapeutic algorithm in our practice. In this issue of REED, Ortiz-Lucas et al. (13) offer a detailed meta-analysis on the efficacy of probiotics for IBS including two relevant contributions. The first one is the categorization of results according to probiotic species. Thus far knowledge on the effects of probiotics has been globally envisaged by jointly collecting the impact of all species together, which is not necessarily wise; in fact, this meta-analysis shows that the effects of different species are dissimilar, hence we should start to consider the notion of probiotics in a more specific manner - using their full names. In analogy with drug treatments, while drug classes exist we only accept effectiveness on an individual basis. Their second interesting contribution is their independent assessment of the various symptoms manifested by IBS. Since not all probiotics are necessarily alike, their effects on various symptoms also vary and, in fact, drug effects are not only assessed from an overall efficacy viewpoint but also individually regarding each complaint.

A tailored assessment of probiotics, as reported in this issue of the Spanish Journal of Gastroenterology, is undoubtedly a first step in the correct and, most importantly, 
useful inclusion of probiotics within the adequate management of patients with IBSprobiotics with full names, that is.

\section{Ángel Álvarez-Sánchez and Enrique Rey}

\section{Department of Digestive Diseases. Instituto de Investigación Sanitaria. Hospital Clínico San Carlos (IdISSC). Madrid, Spain}

\section{REFERENCES}

1. Rey E, Talley NJ. Irritable bowel syndrome: novel views on the epidemiology and potential risk factors. Dig Liver Dis 2009; 41:772-80.

2. Almansa C, Diaz-Rubio M, Rey E. The burden and management of patients with IBS: Results from a survey in spanish gastroenterologists. Rev Esp Enferm Dig 2011;103:570-5.

3. Ford AC, Spiegel BM, Talley NJ, Moayyedi P. Small intestinal bacterial overgrowth in irritable bowel syndrome: systematic review and meta-analysis. Clin Gastroenterol Hepatol 2009;7:1279-86.

4. Pimentel M, Lembo A, Chey WD, Zakko S, Ringel Y, Yu J, Mareya SM, Shaw AL, Bortey E, Forbes WP. Rifaximin therapy for patients with irritable bowel syndrome without constipation. N Engl J Med 2011;364:2232.

5. Yu D, Cheeseman F, Vanner S. Combined oro-caecal scintigraphy and lactulose hydrogen breath testing demonstrate that breath testing detects oro-caecal transit, not small intestinal bacterial overgrowth in patients with IBS. Gut 2011;60:334-40.

6. Lin HC. Small intestinal bacterial overgrowth: a framework for understanding irritable bowel syndrome. JAMA 2004;292:852-8.

7. King TS, Elia M, Hunter JO. Abnormal colonic fermentation in irritable bowel syndrome. Lancet 1998;352:1187-9.

8. Tana C, Umesaki Y, Imaoka A, Handa T, Kanazawa M, Fukudo S. Altered profiles of intestinal microbiota and organic acids may be the origin of symptoms in irritable bowel syndrome. Neurogastroenterol Motil 2010;22:512-5.

9. Quigley EM, Flourie B. Probiotics and irritable bowel syndrome: a rationale for their use and an assessment of the evidence to date. Neurogastroenterol Motil 2007;19:166-172.

10. Bixquert Jimenez M. Treatment of irritable bowel syndrome with probiotics. An etiopathogenic approach at last? Rev Esp Enferm Dig 2009;10:553-64

11. McFarland LV, Dublin S. Meta-analysis of probiotics for the treatment of irritable bowel syndrome. World J Gastroenterol 2008; 14:2650-61.

12. Hoveyda N, Heneghan C, Mahtani KR, Perera R, Roberts N, Glasziou P. A systematic review and meta-analysis: probiotics in the treatment of irritable bowel syndrome. BMC Gastroenterol 2009;9:15.

13. Ortiz-Lucas M, Tobias A, Saz P, Sebastián JJ. Effect of proviotic species on irritable bowel syndrome symptoms: A bring up to date meta-analysis. Rev Esp Enferm Dig 2013;105:19-36 